\title{
Erratum to: Mission design, operation and exploitation of the Gravity field and steady-state Ocean Circulation Explorer (GOCE) mission
}

\author{
Rune Floberghagen - Michael Fehringer - Daniel Lamarre • \\ Danilo Muzi - Björn Frommknecht - Christoph Steiger · \\ Juan Piñeiro • Andrea da Costa
}

Published online: 8 February 2012

(C) Springer-Verlag 2012

Erratum to: J Geod (2011) 85:749-758

DOI 10.1007/s00190-011-0498-3

The title of the manuscript shall be changed to "Mission design, operation and exploitation of the Gravity field and steady-state Ocean Circulation Explorer (GOCE) mission".

This erratum of the manuscript is needed because internal formatting rules and guidelines led to the name of the GOCE mission being improperly reflected in the article title.

The online version of the original article can be found under doi:10.1007/s00190-011-0498-3.

R. Floberghagen $(\bowtie) \cdot$ M. Fehringer · D. Lamarre · D. Muzi ·

B. Frommknecht

Earth Observation Programmes,

European Space Agency, Frascati, Italy

e-mail: rune.floberghagen@esa.int

URL: http://earth.esa.int/goce

C. Steiger · J. Piñeiro $\cdot$ A. da Costa

Human Spaceflight and Operations,

European Space Agency, Darmstadt, Germany 